\title{
Relation between Electric Vehicles and Operation Performance of Power Grid
}

\author{
Gunars VALDMANIS ${ }^{1 *}$, Gatis BAZBAUERS ${ }^{2}$ \\ 1,2Institute of Energy Systems and Environment, Riga Technical University, Āzenes street 12-K1, Riga, \\ LV-1048, Latvia
}

\begin{abstract}
Rapidly increasing number of electric vehicles (EV) is expected in the future. It is important to understand the consequences of this process for operation of power grids. The goal of this study was to determine an impact of increasing number of EV on the economic performance of electricity distribution system, including the impact on users of power distribution infrastructure. Factors, such as expected network load changes and required investment in the networks as well as possible changes in power distribution tariff were considered. Analysis of Latvia's power distribution system shows that the installed capacity significantly exceeds the load. It means that connection of EV charging infrastructure to the system and resulting increase of the system's load may not require additional investments and even could bring a positive economic effect due to better utilization of the infrastructure.
\end{abstract}

Keywords - Clean energy transition; electric mobility; electric vehicles; energy economics; power distribution system; sustainable mobility

\section{INTRODUCTION}

Transport sector is one of the sectors that will have to undergo significant technological changes due to its large greenhouse gas emissions and share of the total anthropogenic emissions. At present, electric vehicles (EV) can be considered as one of the technologies that convincingly starts to replace internal combustion engine vehicles. However, due to high production costs and lack of information on the potential impact of electric cars on environment and socio-economic well-being, initiatives to promote electric mobility often face significant public scepticism. One of the issues that often arises is the costs of required development and maintenance of power grid infrastructure to provide the electric mobility. At the same time, analysis of the actual load and structure of investments in electricity networks suggest that an impact of electric mobility on network operating costs, in contrast to concerns, can be positive in many cases. EV may contribute to the network efficiency. Therefore, the research question of this study is to identify impact of possible dynamics of EV fleet on the required investments in the power networks.

To our knowledge, the technical impacts of EV charging infrastructure on power distribution grid has been studied extensively by many researchers; however, changes in economic performance of distribution networks in a situation, when significant part or all fossil-fuelled passenger cars are replaced with EV, remains relatively uncovered. Meanwhile, the existing studies focusing on the technical effects of electromobility, provide several important facts for related economic analysis, e.g., modelling results prove, that coordinated

* Corresponding author.

E-mail address: gunars_valdmanis@inbox.lv 
strategy for allocation of charging capacities and sufficiently managed charging strategy can increase allowable theoretical penetration of EV in the system up to 6 times [1]. Study in the Germany confirms that technical influence of EV charging strongly depends on the local topology and capacity utilization in a power grid [2]. Thus, research confirms that in cases when the available grid capacities have low overall utilization rate, e.g., up to $30 \%$, on the system level there is no provable direct relation between electric vehicle penetration and investment in or operation costs of the grid. Additional load of EV charging has the same impact on operation of the grid as any other additional demand for electrical energy [3]. It means that in the case of under-utilized grid charging of the electric transport can be used as a strategy to improve overall utilization of the grid and make an economic optimization of the grid [4], [5]. Several other studies also show a strong relationship between optimized and adaptive electrical transport charging infrastructure development strategy and their potential environmental impact in relation to energy losses and carbon emissions [6], [7].

The scientific topicality of this study is due to the fact that during the last decade, and especially in the last year, development of electromobility in Latvia has experienced a rapid growth. It is also expected that policy support for development of electromobility will be strong in the coming years. The experience of electricity network companies shows that in many cases an increase in demand for network services caused by electromobility can be considered as economically favourable development for the network infrastructure. However, depending on different development scenarios of EV, which may be influenced by political decisions, the amount of investment required and the associated benefits and costs for end-users may vary.

Industry expert estimates in Latvia indicate that the development of EV from the viewpoint of electricity network infrastructure is related to two simultaneous trends. The first significant trend, according to the assessment provided by the electricity network operators, is expected investments in electricity distribution systems to ensure safe connection of EV charging points to the network and provision of the required capacity for its future operation. Another important trend is changes in the total load of electricity networks. Data provided by Latvia's electricity transmission and distribution system operators show that the total system capacity is significantly larger than the actual load of power system users, and the load can be increased several times in many cases. For Latvia this is well illustrated by the fact that the total load of Latvia's electricity users registered back in 1990 reached $2000 \mathrm{MW}$, but the annual electricity consumption reached circa 10.7 TWh [8]. Thus, the historic load exceeds the Latvia's average load of 2019 circa two times, but total electricity consumption about 1.4 times. Given that a significant part, i.e. Up to $80 \%$ of electricity network infrastructure costs, remain fixed regardless of consumption, it can be relatively reliably predicted that electricity consumption from EV will not lead to significant increase in electricity infrastructure costs if the existing capacity is sufficient. On contrary, more effective network load utilization may even reduce the unit costs of electricity supplied to users. Therefore, the goal of this study is to determine the influence of EV on the economic and operational performance of power grid, by considering the actual installed capacity of the electricity grid and potential demand of the EV. The analysis includes assessment of the costs and benefits of power grid users in result of changes in the utilization of the grid capacity. Benefits, expressed in monetary terms, provided to a whole society by the avoided carbon emissions due to displacement of fossil fuel in light-duty vehicle sector by EV are also assessed. 


\section{METHODOLOGY}

The modelling is performed by using the existing data of Latvia regarding the total power demand for the needs, other than electric mobility, as well as the total installed capacity of the grid. Several assumptions regarding characteristics of EV and fossil-fuel based passenger vehicles as well as specific $\mathrm{CO}_{2}$ emissions and costs were made (Table 1).

TABLE 1. MAIN PARAMETERS AND ASSUMPTIONS USED FOR THE CALCULATIONS AND RELATED TO CHARACTERISTICS OF TRANSPORT AND $\mathrm{CO}_{2}$ EMISSIONS

\begin{tabular}{ll}
\hline Parameter & Value \\
\hline Average specific electricity consumption of passenger EV, kWh/km [9] & 0.196 \\
Average yearly mileage of passenger EV, km/year [10] & 13000 \\
Average yearly energy consumption of fossil fuel passenger vehicles, kWh/year [10] & 13152 \\
Average $\mathrm{CO}_{2}$ emissions from passenger EV in Latvia, kg/year [10], [11] & 509.6 \\
Average $\mathrm{CO}_{2}$ emissions from fossil fuel passenger vehicles in Latvia, kg/year [10] & 2600 \\
Average required charging capacity per passenger EV, kW & 10 \\
Price of $\mathrm{CO}_{2}$ emissions, EUR/t [12] & 25 \\
\hline
\end{tabular}

The assumption in Table 1 on average yearly energy consumption of fossil fuel passenger vehicle in Latvia is calculated with the help of following statistical data - average mileage of passenger cars per year in Latvia, and the average fuel consumption of passenger cars.

$$
\text { Av. yearlyconsumption }=\text { Yearlymileage } \cdot \text { Av.cons. }(L) \cdot\left(\frac{\mathrm{kWh}}{\mathrm{L}}\right)
$$

Meanwhile, the numbers for calculated emissions from fossil fuel vehicles are calculated according to the statistical average age of cars in Latvia, as well as with the corresponding, applicable European emission standard (for vehicles produced up to year 2009 - Euro IV standard).

$$
\text { Av. yearlyemissions }=\frac{\text { mileage }}{\text { year }} \cdot \frac{0.2}{\mathrm{~km}}
$$

Meanwhile the calculation for the average $\mathrm{CO}_{2}$ emissions from passenger EV in Latvia are obtained with the help of European Commission statistics on the $\mathrm{CO}_{2}$ intensity in production and imported electricity per one kilowatt hour of electricity for European countries, as well as the estimated yearly consumption of electricity per one EV at yearly mileage of $13000 \mathrm{~km}$.

$$
\text { Yearly EV emissions }(\mathrm{kg})=\text { Emissions per } \mathrm{kWh} \cdot 13000 \cdot 0.196
$$

The calculations are made with assumption that the yearly number of investments in power distribution system is maintained in line with the existing level. It is based on assumption that increase in number of EV does not always lead to investment in the grid. Findings of some studies show that during integration of EV charging infrastructure into the grid the grid operators enjoy a wide range of options for optimization of the grid load. Thus, amount of the investments allocated to grids should be viewed as a decision which is mostly related to overall investment and regulatory policy of the grid, or even political decisions, rather than a parameter which is directly linked to demand of consumers. However, the model also includes 
an option that allows to compare scenarios with additional investments in the grid.

TABLE 2. MAIN PARAMETERS AND ASSUMPTIONS USED FOR THE CALCULATION OF DisTRIBUTION GRID PERFORMANCE [13]

\begin{tabular}{ll}
\hline Parameter & Value \\
\hline Installed distribution network capacity, MVA & 6118 \\
Requested distribution network capacity, MVA & 11503 \\
Peak demand in Latvia's grid in 2020, MVA & 1250 \\
Assumed diversity factor for distribution grid, including EV charging & 3 \\
Average yearly capacity fee (fixed cost) in grid, EUR/MVA per year & 2464 \\
Average power distribution fee (the variable part), EUR/kWh & 0.04399 \\
\hline
\end{tabular}

The performed analysis helps to evaluate how the development of EV may improve an economic performance of the existing electricity network infrastructure. It can also be used to model outcome of alternative development scenarios with such variable parameters as additional investments in the grid, changes in structure of electricity tariffs, or change of the tariff. Calculations that show an impact of electricity consumption and investment demand related to EV on the cost of operation of power distribution system were developed. Scientific publications, statistical data and recommendations of managers of electricity infrastructure were used for a set of assumptions used in the research.

The approach, adopted in this analysis, is supported by several earlier research regarding the impact of grid development on promotion of EV and impact of EV transport on grid development. Studies on the development of EV charging infrastructure to date indicate that a significant impact on the demand for different types of EV charging equipment can develop under a number of possible scenarios, each with a potential impact on network load as well as behaviour of users. It has been found that electric car users tend to prefer charging at individual connection points (circa in 50 to $80 \%$ of cases) as well as workplaces (between $15 \%$ and $25 \%$ of cases), and only about $10 \%$ of charges take place in public charging locations [14]. It was also concluded that availability of the charging services in the users' house has a decisive effect on demand for the charging capacity and capacity in different voltage categories of a network. For example, in Germany, where a relatively large population lives in individual houses (with charging available in yard or garage), mainly low power charging (up to $22 \mathrm{~kW}$ ) is demanded, and that demand does not require a significant investment in networks. While in the Netherlands, where significantly lower availability of charging at home has been recorded, demand for public recharging points was larger [15]. These studies confirm that there is no clear correlation between growing charging capacity and actual load of power distribution system. It follows that in cases where network capacity as a whole is able to meet the expected cumulative demand of EV, there is no evidence that the increase in number of EV correlates with network investment, as the network operator can be flexible regarding investment and promote economic usage of the network capacity, thus influencing consumer behaviour and habits [16], [17]. It is also evident that often the density of the charging infrastructure rather than the allocated capacity in each of the charging stations plays a decisive role in promoting EV usage [18], [19]. Studies also point to a very strong correlation between the population structure of specific regions, residential building type, population density and electromobility usage habits, and consequently the development of a specific type of charging infrastructure [14]. For example, it is emphasized that in the Netherlands, where the prevalence and availability of detached houses is relatively low, the country is characterized by the development of slow charging stations, and these stations have 
developed at a very high density. Number of the charging stations is significantly higher and these are located closer to each other than in countries where electric car charging is located at homes and there is a high prevalence of fast charging points [16]. The most important conclusion to be drawn from the studies conducted so far on the development scenarios of the electromobility charging service and its relation to other socio-economic factors is that although the initial development of electromobility is largely dictated by national socioeconomic developments, policy implementation decisions may also be affected, and there may be a situation where electric cars can be used with equal intensity in countries with slow charging service capabilities and countries with widespread fast charging infrastructure [20], [21]. From the viewpoint of the development of a common energy supply infrastructure, this finding is very important, as it indicates that policy makers have to choose several possible infrastructure development scenarios, which also directly affect the impact of measures on electricity networks and network investments [22], [23]. It should be noted that, unlike many other societal energy consumption habits, there is no single common and pronounced trend that accurately reflects the impact of electromobility on network performance. There is no sufficient evidence to suggest that the usage pattern of EV will be significantly different from usage pattern of fossil-fuelled transport, and thus it can be assumed that the peak usage of EV will be achieved in morning hours and evening hours. Historical data also suggest, that transport usage patterns during the day time also have no direct correlation with the demand refuelling or recharging of vehicles, un thus, there is currently no reason to believe that this trend will change as the share of electric vehicles increases and will also be reflected in the performance of the electricity grid [24].

From the electromobility research it can be concluded that the overall design of electric charging stations is normally optimized, which ensures availability of the charging service depending on the mobility habits of the region (e.g. average travel distances, urban or extraurban mobility), and significantly reduces the total charging density of EV in a given area, as well as the required electrical capacity of these charging stations [25]. In many cases the actual location of charging points may be flexible and also take into account a number of other planning aspects, such as the availability of the building area, the interaction of the charging point with other public infrastructure objects (such as tourist destinations or other public service objects) [6]. Findings of the studies indicate that both the need for a particular density of the charging stations in a particular area and the resulting impact on the network depends significantly on the population density, as well as on the technical characteristics and condition of the existing network. Considering these findings, an assessment of the most important technical features of the Latvia's electricity distribution system network, which may affect both the amount of potentially required investments for electromobility development and the network technical and economic performance in the future, was performed in consultation with the specialists of the power distribution company 'Sadales Tîkls'. According to the data compiled by the company 'Sadales Tīkls', the total length of the Latvia's public distribution networks is approximately $93000 \mathrm{~km}$ (excluding independent operators), which means that the total length of the network per 1000 inhabitants is approximately $48.1 \mathrm{~km}[13])$. By comparison, according to statistics from Estonia and Lithuania, i.e. Elektrilevi [26] and ESO, the length of the public distribution network per 1000 inhabitants amounts to circa $45.1 \mathrm{~km}$ in Estonia and $46.1 \mathrm{~km}$ in Lithuania. It means that in Latvia the costs of maintaining the network and recovering capital investments are higher for network users than in neighboring countries. In turn, electricity consumption in 2020, according to the data compiled by Nord Pool Spot, reached $11.84 \mathrm{TWh}$ in Lithuania, 7.95 TWh in Estonia and 7.059 TWh in Latvia showing that also a power consumption per $1 \mathrm{~km}$ of network length is the smallest in Latvia, i.e. the average electricity transmitted per 
$\mathrm{km}$ of the network reached $91 \mathrm{MWh} /$ year in Lithuania, $132.5 \mathrm{MWh} /$ year in Estonia, and $76 \mathrm{MWh} /$ year in Latvia. Although these figures can be considered as a general comparison, which do not provide an accurate insight into the economic aspects of the electricity distribution network, these convincingly indicate significant characteristic of the electricity network in Latvia. Namely, it is characterized by low load per length of the network, which also contributes to lower economic efficiency of the network. From this point of view, it can be concluded that Latvia's electricity network currently has unfavourable economic operating environment and technical preconditions for its operation than in neighbouring countries. Thus, increasing the total electricity network load and national electricity consumption in Latvia is desirable. Such conclusion also results from the basic principles of the common distribution system operator tariff and allowable revenue calculation methodology [27]. From the viewpoint of the company's representatives, it can be concluded that the most significant modernization works and related investments in the network related to diffusion of electromobility are expected in the low voltage part of the network, which is generally characterized by lower specific investment per $\mathrm{km}$. The technical condition of the existing network is relatively good, as confirmed by improvements in the quality and security indicators of network services System Average Interruption Duration Index (SAIDI) and System Average Interruption Frequency Index (SAIFI) [13]. The overall low load of the Latvia's distribution grid is also characterized by comparison of the installed capacity of the grid transformers in the distribution network and the requested capacity by consumers (Table 1). Thus, it can be concluded, that even under the peak consumption conditions the total load of the system remains well below the maximum capacity and less than $30 \%$ of the theoretical capacity of transformers (the actual demand which can be met with the installed capacity of transformers may vary in line with the actual power factor, the ratio of the real power absorbed by the load to the apparent power flowing in the circuit). Therefore, the assessment of the network capacity suggests that the power grid of Latvia is potentially capable to absorb theoretical load which exceeds the existing load even 4 times. Research also suggests that the overall simultaneity factor for EV charging is not significantly different from the overall factor for other needs, with approximately only $78 \%$ of the transport used daily, and the simultaneity factor for EV charging reaching only approximately $50 \%$ for the most extreme scenarios [2]. The assessment confirmed that the overall capacity of the grid remains sufficient to support full replacement of all registered and actively used vehicles (including trucks and passenger buses) in Latvia, which equals to approximately 1 million vehicles. According to the specialists of the company 'Sadales Tìkls', the planned investments and modernization program are also considered to be an important precondition for the development of electromobility, but in general it is not possible to identify the investment that should be directly linked to the demand for services generated by the development of electromobility. In total, the amount of additional required investments for the period from 2022 to 2026 has been identified in the amount of circa 100 EUR million, which makes up the average annual investment demand in the amount of about 20 million EUR, or about $20 \%$ more than the current annual average. Considering the company's total operating income of EUR 320 million, which accordingly reflects the actual costs of the service provided by the company, it can be concluded that the company's investment program for the implementation of these modernization measures corresponds to approximately $6 \%$ of the company's annual turnover. 


\section{ReSUlts AND DiscuSSION}

Results regarding potential reduction of average total costs of power distribution and avoided $\mathrm{CO}_{2}$ emissions were obtained by assuming that a number of $\mathrm{EV}$ changes from the current 1000 to 500000 in the future. With such dynamics of EV development the total electricity consumption in the system increases by approximately $1.248 \mathrm{TWh} /$ year, which is approximately $20 \%$ of the current power consumption. Such increase in the consumption of electricity contributes to additional income to the grid operator, which in turn, after the deduction of applicable costs (mostly - proportional increase of electricity losses), can be used for reduction of the average tariff per $\mathrm{kWh}$ by circa $0.2 \%$. That equals to economic gains of all energy consumers at amount of approximately 0.7 million EUR per year. The results show (see Fig. 1.) that decrease of the tariff (average total costs of power distribution) is relatively small, i.e. $0.9 \%$ in total if the number of EV increases from 1000 to 500000 . Since the scenario envisaged that change in average distribution system tariffs is modelled for EV with increments of 10000 units, the regression function was added in the figure to evaluate how highly the obtained results fit the simple average of the estimated result and confirm the assumed trend. If the number of EV doubles the tariff decreases by $0.017 \%$. This small effect of EV consumption on the tariff can be explained with the overall proportion of the fees for installed capacity and per unit of delivered electricity in the tariff structure for distribution service. Due to the fact that significantly higher proportion of the network fees is attributed to the consumed energy, the economic effect of increased energy consumption is proportionally smaller than would be in the case with higher fixed component in the tariffs.

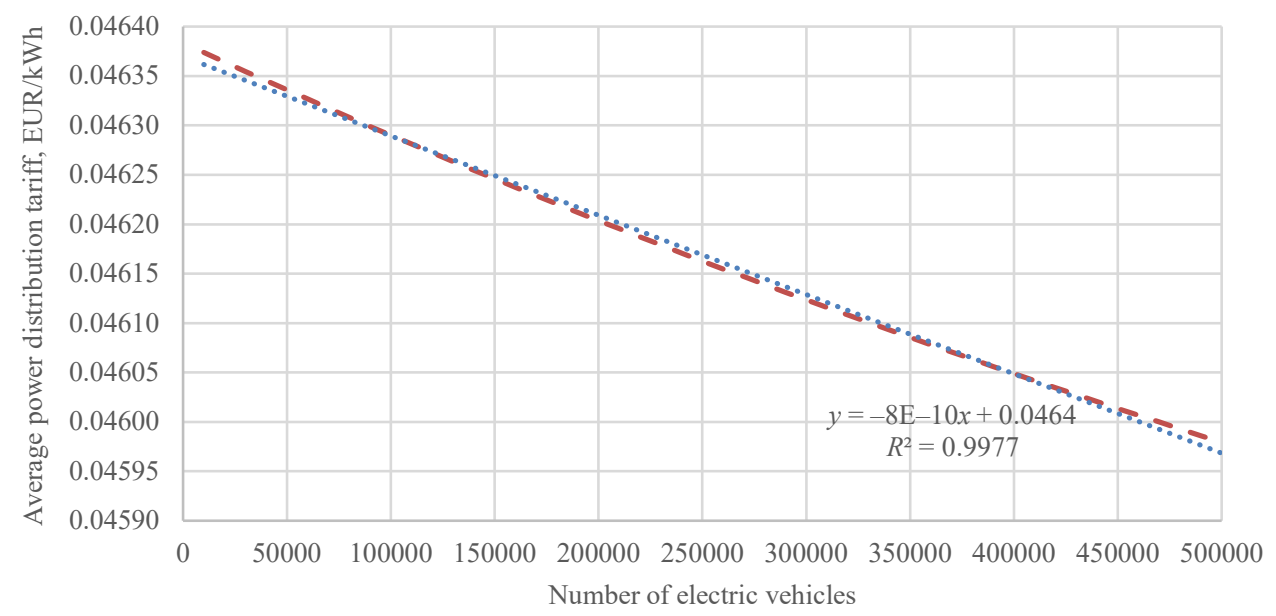

Fig. 1. Average power distribution tariff depending on number of electric vehicles in Latvia (regression function is the dotted line).

More significant socio-economic effect is achieved from potential reduction of $\mathrm{CO}_{2}$ emissions when EV displace fossil fuel-based internal combustion engines. When the number of EV reaches 500000 the avoided costs of $\mathrm{CO}_{2}$ emissions, assuming the $\mathrm{CO}_{2}$ price of $43 \mathrm{EUR} / \mathrm{t}$ (such level was reached by late March 2021) reached circa 45 million EUR/year (see Fig. 2). In another words, each EV results in circa $90 \mathrm{EUR} /$ year of avoided $\mathrm{CO}_{2}$ emission costs with the assumed price of $\mathrm{CO}_{2}$ or $2 \mathrm{t}$ of avoided $\mathrm{CO}_{2}$ emissions by $1 \mathrm{EV}$ per year. It must be also noted that such estimates are based on the approach that the emissions of $\mathrm{CO}_{2}$ from 
fossil fuel cars is $200 \mathrm{~g} / \mathrm{km}$ of travel, and thus reflects pump-to-wheel emissions. For EV the calculation is based on emissions related to the production of the consumed electricity, and is based on the average $\mathrm{CO}_{2}$ emissions per $\mathrm{kWh}$ of the electricity for Latvia, i.e. circa $200 \mathrm{~g} / \mathrm{kWh}$ That figure reflects comparatively conservative scenario, under which approximately $40 \%$ of power demand is met by fossil production sources, and exceeds the historical average calculated $\mathrm{CO}_{2}$ intensity for Latvia by approximately $65 \%$.

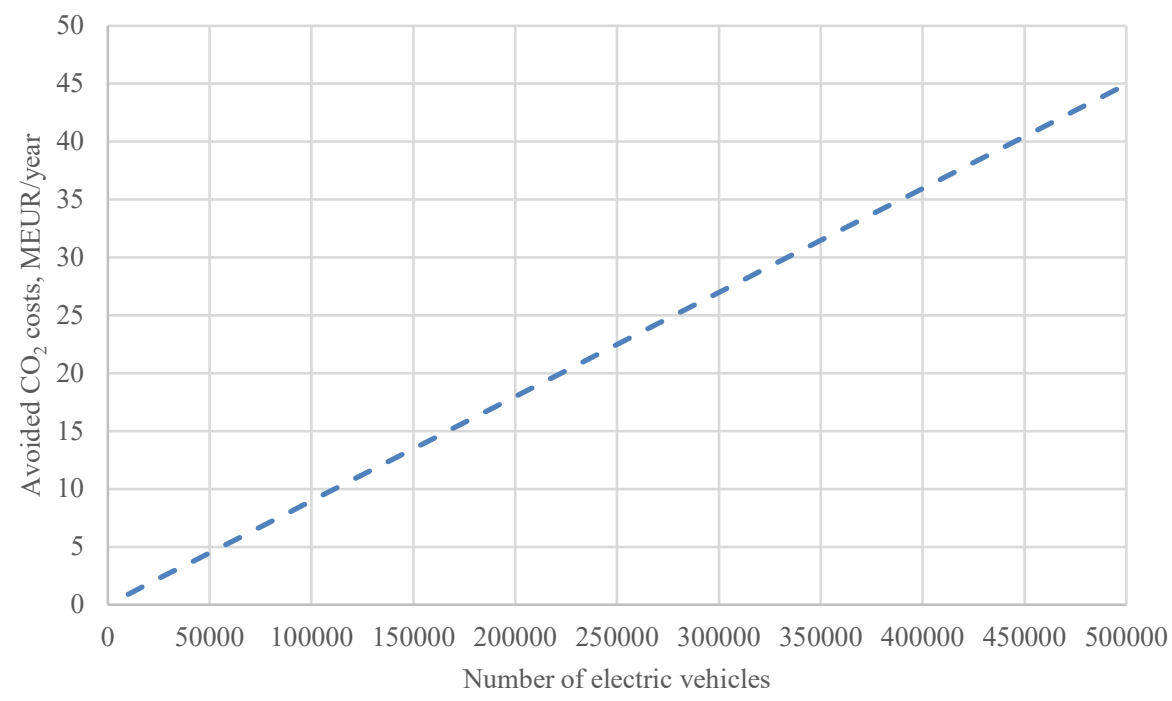

Fig. 2. Avoided $\mathrm{CO}_{2}$ emission costs depending on number of electric vehicles in Latvia.

\section{CONCLUSIONS AND Summary}

The assessment of the potential load and power consumption due to penetration of EV confirms that the installed capacity of the Latvian power grid is sufficient to meet the charging needs of EV even when all fossil transport vehicle fleet is replaced with EV. Therefore, there is no evidence that electrification of the road transport would require significant additional investments in the power grid. Calculation also suggests that the potential increase in power demand would benefit grid operators, and create additional stream of income, which can be used to reduce network charges per unit of delivered electricity. However, it must be noted that the direct economic benefit related to more intensive use of the network can be described as relatively marginal at around $0.2 \%$ or 0.7 million EUR per year for the scenario, when the penetration of EV reaches approximately 500000 units. Meanwhile the value of avoided $\mathrm{CO}_{2}$ emissions is more substantial, and can reach approximately 45 million EUR annually when penetration of EV reaches approximately 500 thousand units. Thus, the study shows that diffusion of EV in the power systems with under-utilized grid capacity can be absorbed with little investment and improvement of the capacity utilization. Benefits from climate perspective, i.e. avoided $\mathrm{CO}_{2}$ emissions and associated costs are even larger. The limitation of this study is that that calculation is static, in a sense, assuming constant characteristics of the vehicles, $\mathrm{CO}_{2}$ price, etc. Calculations were made for various number of EV but not for the scenarios with the most probable development. Future work will improve these shortcomings 
by building system dynamics model where possible dynamics of EV penetration can be assessed.

\section{ACKNOWLEDGEMENT}

This study has been funded by the Latvian Council of Science within the research project 'Simulator for transition to sustainable energy systems (SET4LOW)’ No. 1zp-2020/2-0191.

\section{REFERENCES}

[1] De Hoog J., et al. Electric vehicle charging and grid constraints: Comparing distributed and centralized approaches. IEEE Power and Energy Society General Meeting 2013:6672222. https://doi.org/10.1109/PESMG.2013.6672222

[2] Held L., et al. The Influence of Electric Vehicle Charging on Low Voltage Grids with Characteristics Typical for Germany. World Electric Vehicle Journal 2019:10(4):88. https://doi.org/10.3390/wevj10040088

[3] Bräunl T., et al. Determining the optimal electric vehicle DC-charging infrastructure for Western Australia. Transp Res Part D Transp Environ. 2020:84:102250. https://doi.org/10.1016/j.trd.2020.102250

[4] White C. D., Zhang K. M. Using vehicle-to-grid technology for frequency regulation and peak-load reduction. J Power Sources. 2011:196(8):3972-3980. https://doi.org/10.1016/j.jpowsour.2010.11.010

[5] Deilami S., et al. Real-time coordination of plug-in electric vehicle charging in smart grids to minimize power losses and improve voltage profile. IEEE Trans Smart Grid.2011:2(3):456-467. https://doi.org/10.1109/TSG.2011.2159816

[6] Cardoso G., et al. Optimal investment and scheduling of distributed energy resources with uncertainty in electric vehicle driving schedules. Energy 2014:64:17-30. https://doi.org/10.1016/j.energy.2013.10.092

[7] Foley A., et al. Impacts of Electric Vehicle charging under electricity market operations. Appl Energy 2013:101:93102. https://doi.org/10.1016/j.apenergy.2012.06.052

[8] Staltmanis I. Latvijas Enerğêtika Ceḷā Uz Patstāvību (Latvian Energy on the Road to Independence.). Staltmanis. Riga: VAS Latvenergo, Latvijas energètikịu un elektrotehniḳu zinātniski tehniskā biedrība, 1992. (in Latvian).

[9] EV-database. Energy consumption of full electric vehicles cheatsheet [Online]. [Accessed 22.11.2021]. Available: https://ev-database.org/cheatsheet/energy-consumption-electric-car

[10] CSDD. Transportlīdzekḷi (vizualizācija). Statistika (Vehicle visualization. Statistics.) [Online]. [Accessed 22.11.2021]. Available: https://www.csdd.lv/transportlidzekli/transportlidzekli-vizualizacija

[11] European Environment Agency. Greenhouse gas emission intensity of electricity generation by country - European Environment Agency [Online]. [Accessed 22.11.2021]. Available: https://www.eea.europa.eu/data-andmaps/daviz/co2-emission-intensity-9/\#tab-googlechartid_googlechartid_googlechartid_chart_1111

[12] Ember. Carbon Price Viewer - Ember [Online]. [Accessed 22.11.2021]. Available: https://emberclimate.org/data/carbon-price-viewer/

[13] AS Sadales Tīkls. AS 'Sadales Tīkls' gada pārskats (JSC 'Sadales Tīkls' annual report). Riga: ST, 2019. (in Latvian)

[14] Funke S. Á., et al. How much charging infrastructure do electric vehicles need? A review of the evidence and international comparison. Transp Res Part D Transp Environ. 2019:77:224-242. https://doi.org/10.1016/j.trd.2019.10.024

[15] Muratori M., et al. The role of infrastructure to enable and support electric drive vehicles: A Transportation Research Part D Special Issue. Transp Res Part D Transp Environ. 2020:89:102609. https://doi.org/10.1016/j.trd.2020.102609

[16] Baresch M., Moser S. Allocation of e-car charging: Assessing the utilization of charging infrastructures by location. Transp Res Part A Policy Pract. 2019:124:388-395. https://doi.org/10.1016/j.tra.2019.04.009

[17] Miele A., et al. The role of charging and refuelling infrastructure in supporting zero-emission vehicle sales. Transp Res Part D Transp Environ. 2020:81:102275. https://doi.org/10.1016/j.trd.2020.102275

[18] Clinton B. C., Steinberg D. C. Providing the Spark: Impact of financial incentives on battery electric vehicle adoption. J Environ Econ Manage. 2019:98:102255. https://doi.org/10.1016/j.jeem.2019.102255

[19] Herron C., Wardle J. Technology trajectory and lessons learned from the commercial introduction of electric vehicles in north east england. In Leal Filho W., Kotter R. (eds) E-Mobility in Europe. Green Energy and Technology. Springer, Cham., 2015. https://doi.org/10.1007/978-3-319-13194-8 9

[20] Schroeder A., Traber T. The economics of fast charging infrastructure for electric vehicles. Energy Policy 2012:43:136-144. https://doi.org/10.1016/j.enpol.2011.12.041

[21] Nejad M. M., et al. Online scheduling and pricing for electric vehicle charging. IISE Trans. 2017:49(2):178-193. https://doi.org/10.1080/0740817X.2016.1213467

[22] Bakker S., Maat K., van Wee B. Stakeholders interests, expectations, and strategies regarding the development and implementation of electric vehicles: The case of the Netherlands. Transp Res Part A Policy Pract. 2014:66(1):52-64. https://doi.org/10.1016/j.tra.2014.04.018 
[23] Serradilla J., et al. An evidence-based approach for investment in rapid-charging infrastructure. Energy Policy 2017:106:514-524. https://doi.org/10.1016/j.enpol.2017.04.007

[24] Dharmakeerthi C. H., Mithulananthan N., Saha T. K. Overview of the impacts of plug-in electric vehicles on the power grid. Presented at the 2011 IEEE PES Innovative Smart Grid Technologies, 2011. https://doi.org/10.1109/ISGTAsia.2011.6167115

[25] Jochem P., Szimba E., Reuter-Oppermann M. How many fast-charging stations do we need along European highways? Transp Res Part D Transp Environ. 2019:73:120-129. https://doi.org/10.1016/j.trd.2019.06.005

[26] Majandusaasta aruanne (Annual report.). Tallin: Elektrilevi OÜ, 2019. (in Estonian)

[27] SPRK. Sabiedrisko pakalpojumu regulēšanas komisijas padomes lēmums Nr.172 'Par Akciju Sabiedrības 'Sadales Tīkls' Elektroenerǵijas Sadales Sistēmas Pakalpojuma Tarifiem' (Decision No.172 of the Council of the Public Utilities Commission 'On the Electricity Distribution System Service Tariffs of the Joint Stock Company's 'Sadales Tīkls'.). Latvijas Vestnesis 2019:241. (in Latvian) 